\title{
Immunocytological Localization of Pedal Peptide in the Central Nervous System and Periphery of Aplysia
}

\author{
Wade L. Pearson and Philip E. Lloyd \\ Department of Pharmacological and Physiological Sciences and Committee on Neurobiology, The University of Chicago, \\ Chicago, Illinois 60637
}

\begin{abstract}
Immunocytology using antisera raised to conjugated pedal peptide (Pep) was used to localize the peptide in the CNS and periphery of Aplysia. A total of over 200 neurons in the CNS exhibited Pep-like immunoreactivity. As expected from results presented in the previous paper, immunoreactive neurons were heavily concentrated in the pedal ganglia, primarily in a broad ribbon comprised of about 60 large contiguous neurons on the dorsal side of each ganglion. Smaller and less numerous immunoreactive neurons were found in the other ganglia. A number of neurons primarily located in the abdominal ganglia had dense networks of immunoreactive varicose fibers surrounding their cell bodies. Many immunoreactive axons were observed in peripheral nerves, particularly those nerves leaving the pedal ganglia. Analyses of sections of body wall indicated that Pep-like immunoreactivity was localized to a series of varicose axons that appeared to be associated with vascular spaces, muscle fibers, and other large cells. These axons likely arise from pedal ganglion nerves that were shown to transport large amounts of ${ }^{35} \mathrm{~S}$-labeled Pep to the periphery. These results suggest that Pep is a transmitter-like neuropeptide that is likely to have a number of important physiological actions in Aplysia.
\end{abstract}

The previous paper describes the purification and sequence of a novel ncuropcptide from Aplysia. This peptide, pedal peptide (Pep), was originally identified and postulated to function as a neurotransmitter because it was synthesized predominantly in the pedal ganglia (Lloyd and Connolly, 1989). Further investigation of this hypothesis required a more detailed understanding of the localization of the peptide within the CNS and periphery. A peptide that acts as a transmitter should be localized in specific, identifiable presynaptic cell bodies and in presynaptic terminals in the vicinity of postsynaptic neurons or peripheral structures. In the present study, we report the localization of Pep-like immunoreactivity to such structures in each of the central ganglia in Aplysia, as well as in peripheral tissue. We have also demonstrated that Pep was transported in very large amounts from the pedal ganglia towards the periphery and into body wall.

\footnotetext{
Received Apr. 7, 1988; revised May 19, 1988; accepted June 6, 1988.

We thank C. Saper and C. Breder for instructions in the use of, and access to the fluorescence microscope and $\mathrm{C}$. Connolly for critical reading of the manuscript. This work was supported by NIH Grant NS-23569 and a Whitehall grant.

Correspondence should be addressed to Wade L. Pearson, Department of Pharmacological and Physiological Sciences and Committee on Neurobiology, The University of Chicago, 947 East 58th Street, Chicago, IL 60637.

Copyright (c) 1989 Society for Neuroscience $0270-6474 / 89 / 010318-08 \$ 02.00 / 0$
}

In Aplysia, immunocytology of the CNS has been particularly useful when done on ganglia whole mounts. This procedure expedites the identification of specific cells that either contain immunoreactivity or have immunoreactive varicosities or terminals on their cell bodies. Once identified, such cells can be subjected to more rigorous biochemical and physiological studies. The results from the present study strongly support the proposition that Pep is a transmitter-like peptide with a broad range of functions within both the CNS and the periphery of Aplysia.

\section{Materials and Methods}

Animals. Aplysia californica (25-200 gm) were obtained from Marinus, Inc. (Long Beach, CA), and maintained in circulating artificial sea water (ASW) tanks at $15^{\circ} \mathrm{C}$.

Antisera. Antibodies to Pep were prepared by a commercial source (Berkley Antibody Company, Richmond, CA). Briefly, synthetic Pep conjugated to either BSA or ovalbumin (emulsified with Freund's complete adjuvent) was injected into rabbits for immunization and for subsequent boosts at 3 week intervals. After this regimen, the antisera from both rabbits tested positive on an ELISA using Pep-ovalbumin as antigen. Both antisera, termed PAS-1 and PAS-2, have proven useful for immunocytology, although antiserum PAS- 2 worked at lower dilutions and was primarily used.

Tissue preparation and staining. Immunocytology of whole mounts was carried out using a modification of the methods of Longley and Longley (1986). Animals were immobilized by an injection of isotonic $\mathrm{MgCl}_{2}$, and the CNS and small pieces of tissue were dissected and pinned out in Sylgard-based dishes containing low- $\mathrm{Ca}^{2+}(2 \mathrm{mM} ; 0.2 \times$ normal), high- $\mathrm{Mg}^{2+}(110 \mathrm{mM} ; 2 \times$ normal) $\mathrm{ASW}$. The ring ganglia were generally pinned so that the pleural ganglia were positioned lateral and rostral to the pedal ganglia. The ASW was replaced with a fixative solution of $4 \%$ paraformaldehyde, $30 \%$ sucrose in $0.1 \mathrm{M}$ phosphate buffer ( $\mathrm{PB}, \mathrm{pH} 7.4$ ). The tissue was fixed for 4-8 hr at room temperature or overnight at $4^{\circ} \mathrm{C}$. After fixing, the tissue was washed briefly in PB, then in several changes of PB containing 1\% Triton X-100 (Kodak or Aldrich) and $0.1 \%$ sodium azide for a day. During this wash period, the whole-mount ganglia were manually desheathed. Tissue destined for sectioning was pinned out in Sylgard molds and embedded for frozen sectioning in $10 \%$ gelatin, $10 \%$ sucrose, $3 \%$ paraformaldehyde in Tris-buffered saline $(9 \% \mathrm{NaCl}, 20 \mathrm{~mm}$ Tris $\mathrm{HCl}, \mathrm{pH} 8.2)$. Frozen sections (16-24 $\mu \mathrm{m})$ were cut on a sliding microtome and transferred to PBS $(0.14 \mathrm{M} \mathrm{NaCl}, 0.01$ $\mathrm{M}$ phosphate at $\mathrm{pH} 7.4$ ) in mesh-bottomed incubation wells for staining. For both sections and whole mounts, nonspecific binding of antibodies was blocked by incubating the tissue in a blocking solution consisting of PBS with $1 \%$ Triton $X-100,0.1 \%$ sodium azide, and either $4 \%$ normal goat serum (NGS; Tago) or 1\% NGS, $4 \%$ low-fat dairy milk. Both primary antiserum (PAS-2) and secondary antiserum, a goat anti-rabbit IgG conjugated with fluorescein isothiocyanate (GAR-FITC; Tago), were diluted in this blocking solution. Incubations followed the timetable and concentrations given in Table 1 . Sections and whole mounts were coverslipped in mounting medium consisting of $0.5 \% n$-propyl gallate in a 1:6 PBS:glycerol solution ( $\mathrm{pH} 8.5$ ).

Specificity of staining was tested by preabsorbing diluted PAS- 2 with $10 \mu \mathrm{M}$ Pep for $16 \mathrm{hr}$ at $4^{\circ} \mathrm{C}$, centrifuging at low speed, and using the 

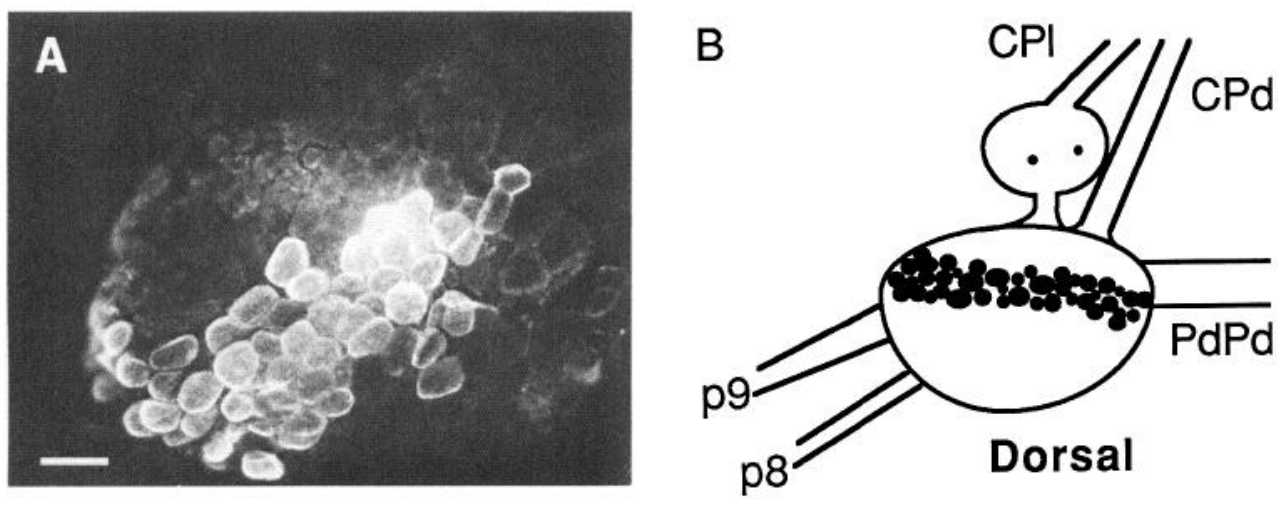

Figure 1. IR-Pep in the pedal ganglia. $(A)$ Photomicrograph and $(B)$ drawing of the dorsal surface of the left pedal ganglion. Immunoreactive neurons are located in a ribbon passing over the surface of the ganglion. $(C)$ Photomicrograph and $(D)$ drawing of the ventral surface of the left pedal ganglion. The immunoreactive cells on the medial and lateral edges of the ganglion appeared to be the dorsal cell band extending around to the ventral surface. The pleural ganglia contained only 1 or 2 immunoreactive cells. Only the left pedal and pleural ganglia are shown, but identical symmetrical staining was observed in the right ganglia. Only selected connectives and peripheral nerves are shown. $C P l$, cerebral-pleural connective; $C P d$, cerebral-pedal connective; $P d P d$, pedal commissure; $p 8$ and $p 9$, pedal nerves 8 and 9 . Scale bars, $200 \mu \mathrm{m}$.

upper portion of supernatant for immunocytology. Neither Pep-absorbed antiserum nor preimmune serum produced specific staining, while antisera treated in parallel but incubated with $\mathrm{SCP}_{\mathrm{A}}, \mathrm{FMRFamide}$, or without peptide stained normally. Slides were photographed with a Leitz Orthoplan fluorescence microscope.

Transport studies. Transport experiments were carried out using methods similar to those described by Lloyd (1988). Pedal ganglia were dissected from large animals, leaving the posterior pedal nerve, $\mathrm{p} 9$; (Hening et al., 1979) attached and intact. The length of nerve p9 was measured in the immobilized animal before it was removed. All other processes were severed and the individual pedal ganglia and attached nerves were transferred to incubation dishes. In an experiment designed to determine if Pep was transported into the peripheral tissue, an additional nerve from the lateral portion of the pedal ganglion and an attached piece of body wall were also left intact.

The ganglion-nerve-body wall complex was placed in transport dishes containing $25 \%$ isotonic $\mathrm{MgCl}_{2}: 75 \%$ ASW. The transport dishes had Sylgard bases into which polypropylene cylinders were embedded as subchambers. Pedal ganglia were pinned in the subchamber, and the nerves were run through Vaseline occluding a slit in the subchamber wall. The solution in the large outer chamber was then changed to $25 \%$ Aplysia blood, 75\% ASW, $0.01 \%$ glucose, antibiotics (penicillin, 25 units $/ \mathrm{ml}$; streptomycin, $25 \mu \mathrm{g} / \mathrm{ml}$ ), $0.01 \% 2$-mercaptoethanol, and 0.1 mm cold methionine. The inside chamber was changed to $50 \%$ Aplysia blood, $50 \% \mathrm{ASW}, 0.01 \%$ glucose, antibiotics, $0.01 \% 2$-mercaptoethanol, and $0.5 \mathrm{mCi} / \mathrm{ml}{ }^{35} \mathrm{~S}$-methionine (Amersham). After $18-24 \mathrm{hr}$ labeling periods at $15^{\circ} \mathrm{C}$, chase periods of $6-30 \mathrm{hr}$ in ASW, $0.01 \%$ glucose, antibiotics, $0.01 \% 2$-mercaptoethanol, and $1 \mathrm{~mm}$ methionine were used. All solutions were cold-sterilized $(0.2 \mu \mathrm{m}$ filtered). In several experiments, $10 \mathrm{~mm}$ colchicine (Sigma) was added to all solutions to inhibit transport.

After incubation and chase periods, the nerve was cut from the ganglia, pinned at half its original length, washed twice with low- $\mathrm{Ca}^{2+}$, high$\mathrm{Mg}^{2+} \mathrm{ASW}$, covered with a solution of $50 \%$ ASW: $50 \%$ propylene glycol at $0^{\circ} \mathrm{C}$, and freeze-substituted at $-20^{\circ} \mathrm{C}$ for $30 \mathrm{~min}$. The nerve was then cut into $1 \mathrm{~cm}$ segments, each piece transferred to polypropylene tubes containing $0.02 \mathrm{M}$ trifluoroacetic acid (TFA) plus $2 \mathrm{nmol}$ cold synthetic
Pep. Labeled peptides were extracted from the nerve segments, partially purified by RP-HPLC, and quantified by liquid scintillation counting as described in the previous paper (Lloyd and Connolly, 1989).

\section{Results}

Pep-like immunoreactivity in the pedal ganglia

Pep was originally identified as a potential neuropeptide based on the observation that it was synthesized predominantly in the pedal ganglia. In accordance with this observation, a large number of cell bodies in the pedal ganglia contained Pep-like immunoreactivity (IR-Pep). These cells were located primarily in a large band on the dorsal surface that runs in a transverse line from just caudal of the pedal commissure to ventral and rostral of peripheral nerve $\mathrm{p} 9$ (Fig. 1). This band is from 3 to 5 cells

Table 1. Incubation times

\begin{tabular}{lll} 
& \multicolumn{2}{l}{ Incubation time (hr) } \\
\cline { 2 - 3 } Procedure & Sections & Whole mounts \\
\hline $\begin{array}{l}\text { Initial blocking solution } \\
\quad \text { wash }\end{array}$ & 6 & 24 \\
Primary antiserum & $12-16$ (PAS-2, & 24 (PAS-2, \\
& $1: 500)$ & $1: 250)$ \\
Blocking solution wash & 4 & 24 \\
Secondary antibody & 4 (GAR- & $16-24$ (GAR- \\
Blocking solution wash & 2 & FITC, 1:100) \\
PBS wash (no Triton & $1-2$ & $8-16$ \\
X-100) & & $2-4$
\end{tabular}




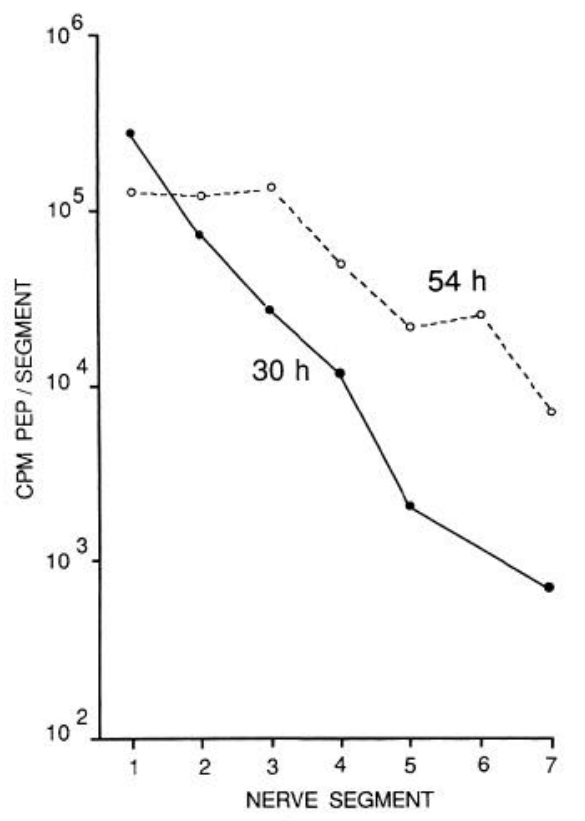

Figure 2. Transport of Pep in the nerve $9(p 9)$. Newly synthesized Pep was labeled with ${ }^{35} \mathrm{~S}$-methionine for $24 \mathrm{hr}$ in a pedal ganglion/nerve preparation in organ culture, and chased for $6 \mathrm{hr}(30 \mathrm{~h}$; solid line $)$ or $30 \mathrm{hr}$ ( $54 \mathrm{~h}$; dashed line). Nerves were then cut into $2 \mathrm{~cm}$ segments, extracted, and run on HPLC. Labeled Pep was found in the last segment of the nerve (12-14 cm from ganglia) after only $30 \mathrm{hr}$. After an additional $24 \mathrm{hr}$, the amount of labeled Pep at the end of the contralateral nerve was over 10 -fold greater.

wide and about 15 cells long and contained approximately 60 large neurons with cell bodies ranging from 50 to $150 \mu \mathrm{m}$ in diameter (in small adult animals). The cell bodies in this band are not restricted to any one sector of the ganglion as delineated by connective tissue septa (Hening et al., 1979). The band of cells extends around to, and was visible on, the ventral surface of the ganglia, where several smaller groups of immunoreactive cells were also located (Fig. 1).

\section{Pep in the periphery}

The pedal ganglia provide the primary central innervation of large regions of the foot and body wall (Hening et al., 1979). Perhaps every peripheral nerve leaving the pedal ganglia and a majority of nerves leaving from other central ganglia contained immunoreactive axons. As expected, these axons were largest and most common in pedal nerves. The posterior pedal nerve (p9) was used to determine if Pep was transported from the pedal ganglia toward the periphery of the animal. Transport of Pep was monitored by incubating isolated pedal ganglia in ${ }^{35} \mathrm{~S}$ methionine and measuring the appearance of labeled Pep in segments of nerve $\mathrm{p} 9$ (Fig. 2). The results indicate that labeled Pep was transported to the end of $\mathrm{p} 9$, a distance of $12-14 \mathrm{~cm}$, in $30-36 \mathrm{hr}$ at $15^{\circ} \mathrm{C}$. This represents a maximal transport rate of about $100 \mathrm{~mm} / \mathrm{d}$. Transport was also measured in the contralateral p9 nerve $24 \mathrm{hr}$ later, by which time much larger quantities of labeled Pep had been transported to distal segments of the nerve. In another experiment, labeled Pep was shown to be transported via an unidentified pedal nerve into peripheral body wall. This nerve was chosen because the distance between the ganglia and body wall was considerably shorter than for $\mathrm{p} 9$. Colchicine (10 mM) greatly reduced transport of Pep to proximal

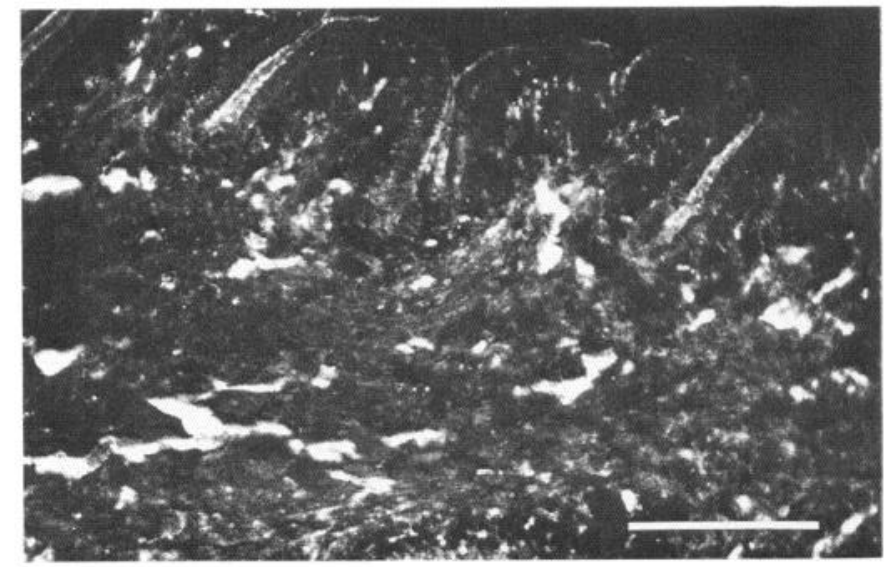

Figure 3. IR-Pep in a section of body wall. Intense immunoreactive large varicosities or neurites were present in the tissue below and parallel to the outer skin. As shown near the middle of the photomicrograph, immunoreactive fibers also projected into the center of many small protrusions of the body wall, suggesting that each was innervated. The top of the photograph shows the outer surface of the skin, which was lightly fluorescent. This fluorescence was a property of the skin itself and was not due to fluorescein in that it was visible with other filter systems (i.e., rhodamine). This section was taken from the mesotegument of the animal (see fig. 4 in Hening et al., 1979). Scale bar, 100 $\mu \mathrm{m}$.

regions of the nerves and completely blocked transport to more distal regions (i.e., more than $2 \mathrm{~cm}$ away from the ganglia).

Immunocytology of transverse sections of body wall from tegument or foot revealed very intense IR-Pep in evenly distributed fibers and what appeared to be large varicosities just below the surface of the skin. Immunoreactive fibers also projected into the centers of many of the small protrusions observed at the outer surface of the skin (Fig. 3) and were occasionally seen in close proximity to large cells that had a glandular appearance. The staining described above was absent when the antiserum was preabsorbed with $10 \mu \mathrm{M}$ Pep. However, the very outermost portion of the skin was also mildly fluorescent. This was an intrinsic property of fixed skin tissue since preabsorption of the antiserum did not alter this fluorescence nor did the use of filters that were opaque to fluorescein.

IR-Pep was also present in cell bodies, neuropil, and terminals in other ganglia

As reported in the previous paper, Pep synthesis was detected in the other ganglia but at much lower levels than in the pedal ganglia. Consistent with this observation, immunoreactive cell bodies were observed in other ganglia, although they were smaller and much less common than in the pedal ganglia.

Each buccal ganglion consistently contained two pairs of moderately sized (diameter, 60-70 $\mu \mathrm{m}$ ) immunoreactive neurons (Fig. 4). One pair was generally located near the middle of the rostral face of the ganglion, just on the edge of the ventral cluster of motor neurons. These immunoreactive cells were located on top of a fiber tract and appeared to send axons into the buccal commissure and possibly out the radula nerve. Adjacent to these large cells was a cluster of 5-8 small $(\sim 15 \mu \mathrm{m})$ immunoreactive cells. The second pair of larger immunoreactive neurons was located at the lateral margins of the ganglia. Fibers containing IR-Pep were often seen in several of the nerves, as well as in the cerebral-buccal connective. In several preparations, a single large cell in the medial portion of the caudal surface was covered 

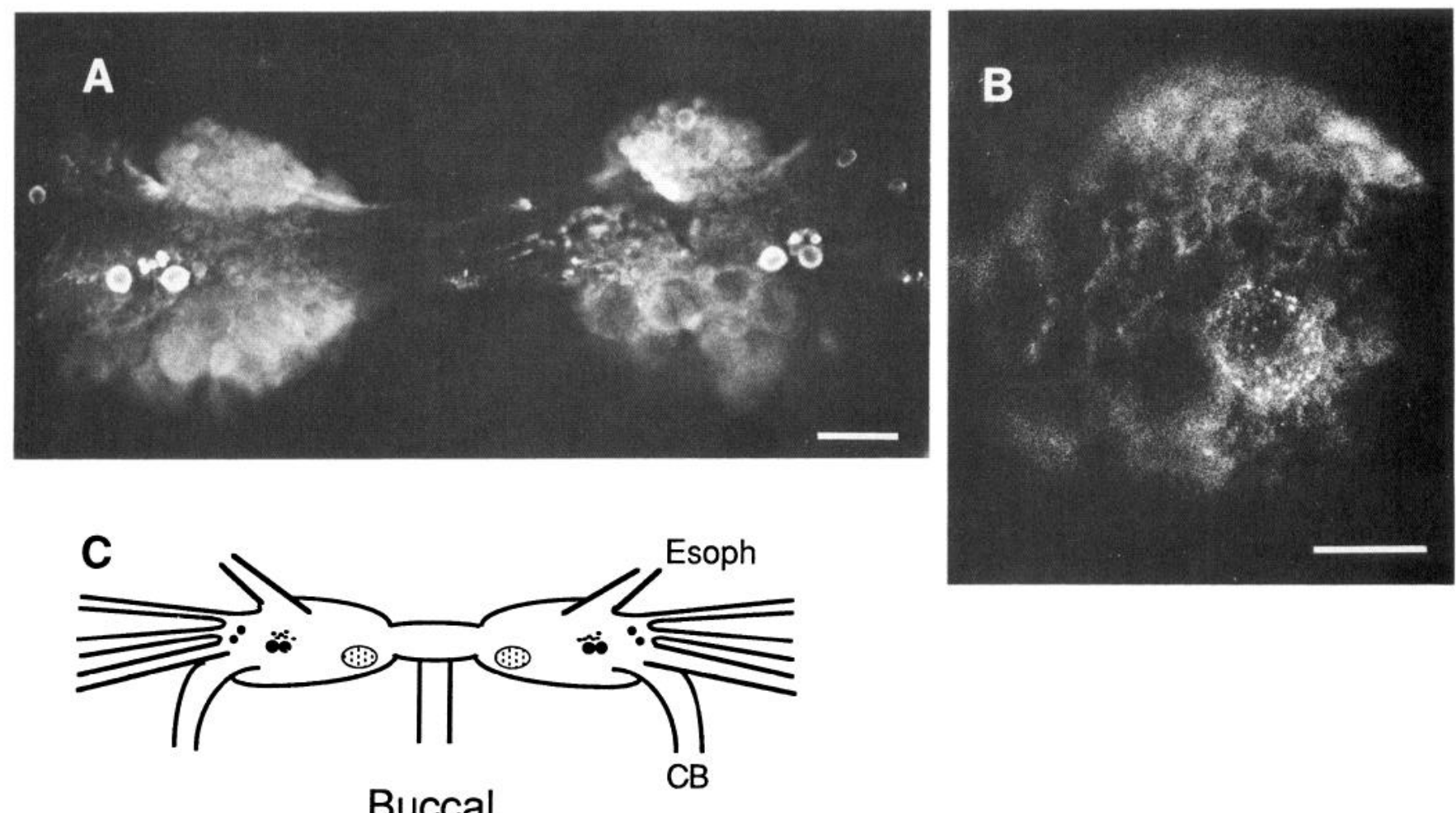

Figure 4. IR-Pep in buccal ganglia. A, Photomicrograph of a whole mount of the paired buccal ganglia shows 2 immunoreactive cell groups on the rostral surface of each ganglion. The most prominent group was located over the fiber tract running into the buccal commissure just on the dorsal edge of the cluster of large ventral cells. This group consists of a pair of moderately sized $(60-80 \mu \mathrm{m})$ and several smaller (15 $\mu \mathrm{m})$ cells. This group appeared to send axons into the buccal commissure and probably out the radula nerve. The other group can be seen as a pair of immunoreactive cells $(40 \mu \mathrm{m})$ on the lateral edges of the ganglia. These neurons were slightly below the plane of focus. Scale bar, $200 \mu \mathrm{m}$. $B$, Photomicrograph of the caudal surface of a left buccal ganglion showing a single neuron covered with immunoreactive varicosities. Scale bar, $100 \mu \mathrm{m}$. $C$, Drawing indicating the typical position of Pep-IR in the buccal ganglia. Stippled circles indicate the position of cells covered with immunoreactive varicosities on the caudal face of each ganglion, and filled circles show the position of immunoreactive somata on the rostral surfaces of the ganglia. $C B$, cerebralbuccal connective; Esoph, esophageal nerve.

with intensely immunoreactive varicosities (Fig. 4B). Similar staining was also repeatedly observed on specific neurons in the abdominal ganglia, as reported below.

In the cerebral ganglia, IR-Pep was present in several cell bodies, and there was relatively intense staining of fibers in the neuropil. The largest immunoreactive neurons were a pair of moderately sized cells $(70-80 \mu \mathrm{m})$ located adjacent to each giant cerebral neuron (C1) (Fig. 5). Many smaller immunoreactive neurons were also observed (Fig. $5 B$ ). All of the immunoreactive neurons in the buccal and cerebral ganglia were bilaterally symmetric.

Although the pleural ganglia neuropil were intensely immunoreactive, these ganglia contained the fewest neuronal cell bodies with IR-Pep. Intense staining of cell bodies, when observed at all, was localized to 1 or 2 small neurons. The large number of varicosities in the neuropil suggests that Pep may be physiologically active on the pleural ganglia neurons.

In each of the pleural, cerebral, and buccal ganglia there were cell bodies that occasionally appeared to be weakly immunoreactive. This staining was not consistent and, when observed, was always faint. This contrasts with the other immunoreactive neurons in these ganglia, which stained intensely and consistently. It is possible that these lightly stained neurons express Pep at low levels or contain another peptide that cross-reacts with the Pep antisera. At present, we have no way of distinguishing between these possibilities.
The abdominal ganglia contained only a few cell bodies that were consistently immunoreactive (Fig. 6). A cluster of 6-8 small $(\sim 40 \mu \mathrm{m})$ positive cell bodies were located on the left ventral surface of the ganglia, just lateral and usually adjacent to cell L5 (Fig. 7) (Frazier et al., 1967). In the caudal portion of the ventral left hemiganglion, a moderately sized $(\sim 100 \mu \mathrm{m})$ immunoreactive cell was often seen in the vicinity of identified neuron L10. Several other immunoreactive neurons in the abdominal ganglia were not consistently observed. In 2 of the 5 ganglia in which the ventral side was desheathed, a single neuron in the right ventral hemiganglion stained intensely. The cell appeared to be of moderate size in a ganglion from a small animal, but of relatively smaller size in a ganglion from a larger animal. Similar changes in the relative sizes of neurons have also been observed for SCP-immunoreactive neurons in the buccal ganglia (Lloyd et al., 1985). The dorsal surface contained 1 or 2 immunoreactive neurons $(\sim 100 \mu \mathrm{m})$ in the vicinity of cells L7 and L8. These cells were observed in 3 of 5 abdominal preparations in which the dorsal surface was desheathed. These inconsistently observed neurons were all located on the lateral margins of the ganglia. Antibodies do not penetrate the connective tissue sheath, so staining was observed only on the desheathed surface of the ganglia and only one surface was desheathed in any given preparation. We suspect that the positions of these neurons shift subtly so they were not consistently observed from the same side. 

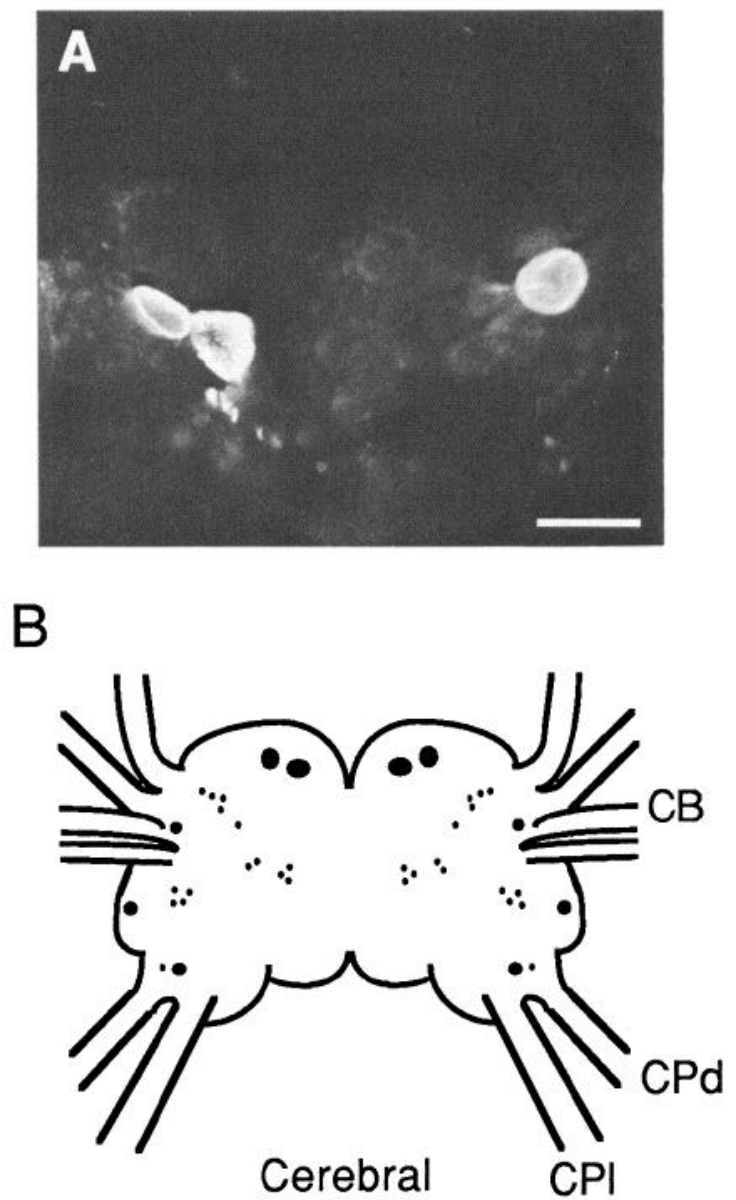

Figure 5. IR-Pep in the cerebral ganglia. A, Photomicrograph of rostral region of the dorsal surface of a cerebral ganglia whole mount. Each ganglion contained a prominent pair of immunoreactive neurons that were adjacent to the giant cerebral neuron $(\mathrm{Cl})$. The second cell of the pair in the right hemiganglion was out of focus below the visible neuron. Scale bar, $100 \mu \mathrm{m}$. $B$, Drawing indicating the approximate positions of immunoreactive cell groups in the cerebral ganglia. The large cells in the rostral portion were visible from the dorsal surface, while the smaller immunoreactive somata were most common on the ventral surface. Cells located in lateral margins of the ganglia could often be visualized from either side of the ganglia.

A striking feature of the abdominal ganglia is the extent to which immunoreactive terminals were observed on cell bodies (Figs. 6A, 7). Terminals were distributed over the somata of neurons tentatively identified as L2, L3, L5 and 2 large neurons in the region of L10, L12, and L13 (Fig. 7). Many smaller cells that are not individually identifiable also had immunoreactive terminals on their somata. These included moderate-sized cells in the dorsal left hemiganglion and a group of similarly sized

Figure 6. IR-Pep in the abdominal ganglion. $A$, Photomicrograph of the dorsal surface of a whole mount. One large immunoreactive neuron was present in the left hemiganglion. This cell was often accompanied by another immunoreactive cell in a lower focal plane. Note the 2 large cells covered with synaptic terminals at the rostral margin of the left hemiganglion. These cells appeared to be neurons L2 and L3. Several smaller cells in the caudal half of the ganglia were also covered with immunoreactive terminals. Scale bar, $200 \mu \mathrm{m}$. B, Drawing of the dorsal surface of the abdominal ganglion showing typical staining pattern. The stippled circles indicate the positions of cells covered with immunoreactive terminals evenly distributed on their cell bodies, while the filled
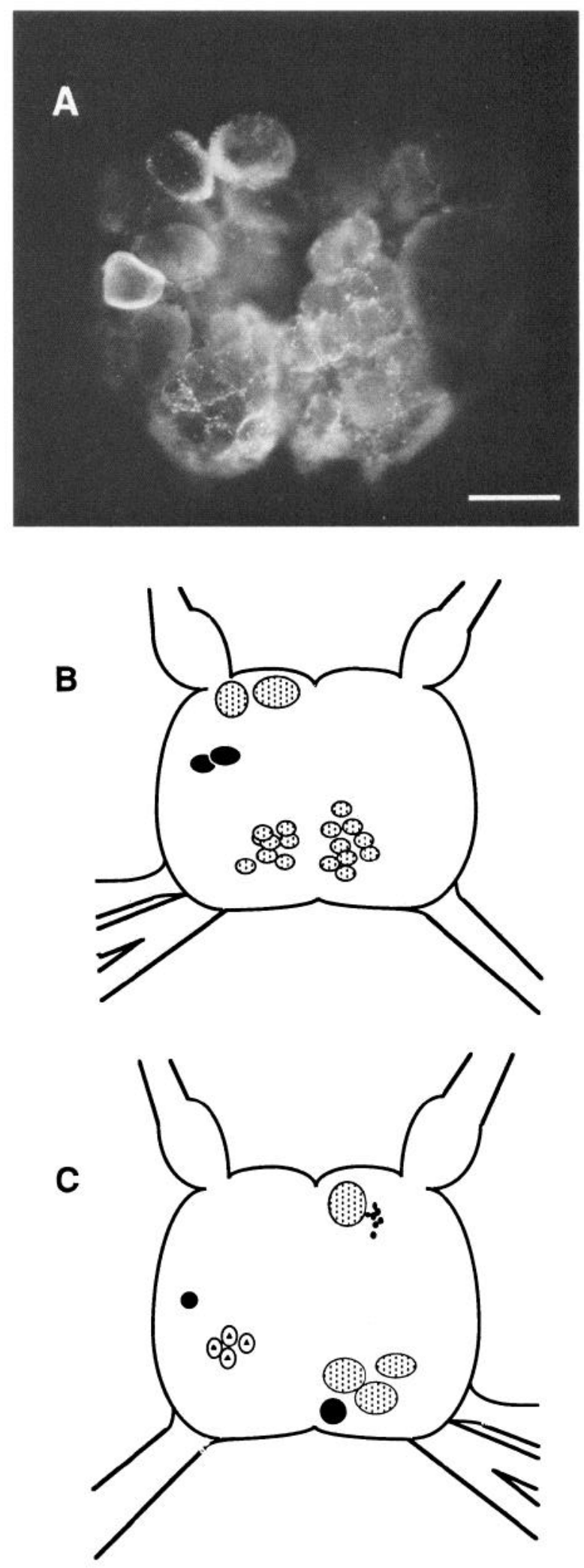

\section{Abdominal}

circles show the positions of immunoreactive somata. $C$, Drawing of the ventral surface of the abdominal ganglion showing typical staining pattern. Circles with triangles indicate cells that had clustered immunoreactive terminals on their cell bodies (see Fig. $7 D$ ). The large cell covered with synaptic terminals in the left rostral hemiganglion was L5 (see Fig. 7, $A, B$ ). 

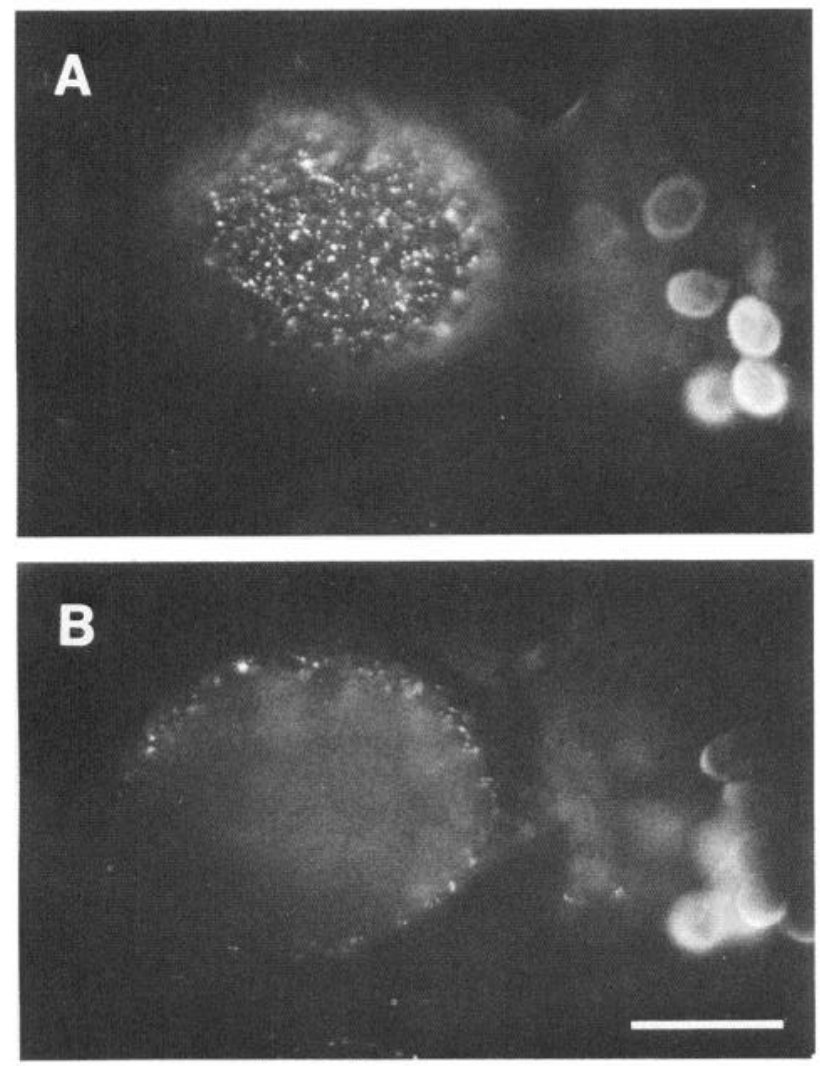
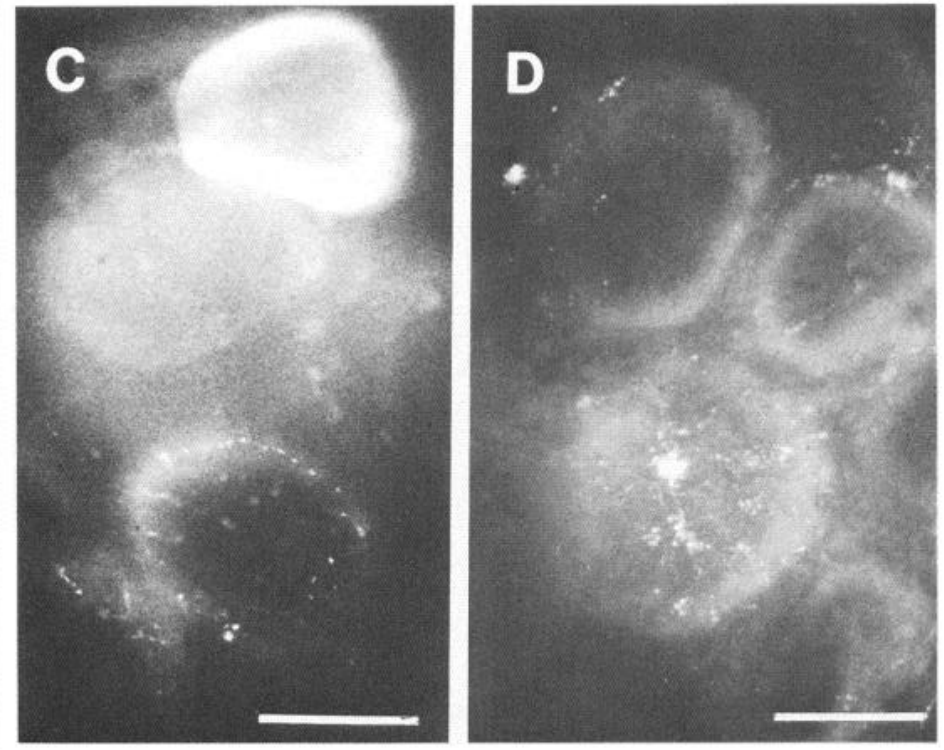

Figure 7. Higher-power photomicrograph of IR-Pep in whole mounts of the abdominal ganglion. $A$ and $B$, Two focal planes of neuron L5 showed that immunoreactive terminals uniformly covered the surface of the cell. This was the distribution of terminals most often observed on cell bodies, although terminals were generally more dense on L5 than on other neurons. Note the group of immunoreactive smaller cells ( $\sim 40 \mu \mathrm{m})$ lateral to L5. In $A$, plane of focus was on the surface of L5, while in $B$, a lower focal plane was used. $C$, Immunoreactive cell body and terminals from the dorsal surface of the left rostral quadrant. Cell with synaptic terminals on its surface at the bottom of the picture was probably L2, while the immunoreactive neuron at the top of the picture was not identified. Rostral edge of the ganglia is located at the bottom of the picture. $D, 3$ neurons in the ventral right hemiganglion with clustered synaptic terminals. These terminals were observed regularly on the surface of neurons in this cell group. Scale bars, $100 \mu \mathrm{m}$.

cells in the same relative position in the right hemiganglion, adjacent and medial to the giant cell R2 (Fig. 6). The terminals on the cells described above were uniformly distributed. However, a group of neurons in the caudal portion of the right ventral hemiganglion also consistently had immunoreactive terminals that were clustered into a few discrete patches per cell body (Fig. $7 D$ ). These terminals were consistently observed on neurons in the same area in whole mounts which also contained many other neurons with uniformly distributed terminals. Thus, clustered terminals appear to represent a morphologically distinct innervation. Immunoreactive axons were present in both pleuralabdominal connectives and in the genital, pericardial, and siphon nerves.

\section{Discussion}

IR-Pep is widely distributed within the central and peripheral nervous systems of Aplysia. Conventional controls for immunocytology were carried out and suggested that the staining observed was specific for Pep. Although no immunocytological control or even series of controls can definitely identify an immunoreactive substance (Landis, 1985), there are several reasons to believe that all or most of the IR-Pep observed in the present study was associated with the presence of authentic Pep. First, Pep must certainly be present in high concentrations in Aplysia ganglia because it was purified and sequenced using the same tissue as a source for the peptide (Lloyd and Connolly, 1989). Second, there were several significant parallels between the presence of IR-Pep and the synthesis and transport of Pep labeled with radioactive amino acids in vivo and identified by HPLC. The distribution of immunoreactive neuronal cell bodies within ganglia closely parallels independent measurements of the rates of Pep synthesis in those same ganglia (Lloyd and Connolly, 1989). In addition, very large quantities of immunoreactivity were present in neurons in the pedal ganglia, in varicosities in the body wall, and in axons of nerves running between them, which were also shown to transport ${ }^{35} \mathrm{~S}$-labeled Pep. Even with these parallels, we cannot state with certainty that any individual Pep-immunoreactive neurons actually contains Pep. However, procedures have been developed that permit individual neurons to be physiologically identified and stained, and the peptides they synthesize determined unequivocally (Cropper et al., 1987).

\section{$I R$-Pep in the CNS}

Each pedal ganglion contains a group of approximately $60 \mathrm{im}$ munoreactive neurons that form a contiguous ribbon over the dorsal surface of the ganglia, as well as smaller cell groups on the ventral surface. Apparently, the cell bodies of these immunoreactive neurons are the source of the very large quantities of Pep that can be isolated from the pedal ganglia. Using the 
value of $1 \mathrm{nmol}$ per pair of pedal ganglia (Lloyd and Connolly, 1989), and our cell count, each of the large immunoreactive neurons in the pedal ganglia contains about 5-10 pmol Pep. Although this may appear to be an extremely large amount of peptide to be present in single neurons, it is actually very similar to the amount of the SCPs measured in 2 large prominent SCPimmunoreactive neurons in the buccal ganglia (Lloyd et al., 1985).

Immunoreactive neurons were considerably less abundant and, with a few exceptions, much smaller in the other ganglia. Immunoreactive fibers and varicosities were present in the neuropil of each of the ganglia. Finally, the cell bodies of individual neurons in several ganglia were covered with networks of fibers and varicosities. Immunoreactive networks on cell bodies have been observed for biogenic amines such as 5-HT, as well as a number of other neuropeptides in Aplysia. Interestingly, we observed several different patterns of IR-Pep innervation on individual neurons. Two patterns involved networks of fibers and terminals on the cell bodies of neurons. Another type of innervation was presumed to occur in the neuropil since immunoreactive fibers and varicosities were common in this structure. Different patterns of innervation have previously been observed for serotonergic terminals in the abdominal ganglia, where the patterns have been correlated with the nature of the physiological responses to 5-HT (Kistler et al., 1985). Localization of IRPep to discrete neural elements lends strong support to the hypothesis that Pep functions physiologically as a neuropeptide transmitter or modulator within the Aplysia CNS.

Overall, there appears to be little overlap between neurons with IR-Pep and neurons stained with antisera to other amines and peptides. These include cgg-laying hormonc (Chiu and Strumwasser, 1981), 5-HT (Goldstein et al., 1984; Ono and McCaman, 1984; Kistler et al., 1985; Longley and Longley, 1986), gastrin/CCK-like peptides (Vigna et al., 1984; Ono, 1986), FMRFamide (Brown et al., 1985; Schaefer et al., 1985; Lloyd et al., 1987), and histidine-rich basic peptide, found in neurons R3-R13 (Kreiner et al., 1984). However, it is possible that a small subset of Pep-positive neurons in the pedal ganglia may overlap with 5-HT- or gastrin/CCK-positive neurons. We are currently investigating this possibility.

\section{IR-Pep in the periphery}

Prominent immunoreactive axons were abundant in many of the nerves leaving the pedal, cerebral, and abdominal ganglia to innervate peripheral regions of the animal. Selected nerves were shown to transport large quantities of Pep to peripheral structures via fast axonal transport, where immunocytology revealed that Pep was present in varicose axons associated with what appeared to be vascular spaces, muscle fibers, and glandular cells. Pep was transported down pedal nerves at rates as high as $100 \mathrm{~mm} / \mathrm{d}$. This rate is somewhat higher than has been reported for transport of glycoproteins or conventional transmitters in Aplysia (Schwartz, 1979). These high rates probably reflect the very high sensitivity of the sampling procedure for Pep, although it is possible that the rates for peptide transport are somewhat higher than for other substances. Transport of neuropeptides in Aplysia has previously been studied in components of the feeding system (Lloyd, 1988). Transport of Pep was quantitatively several orders of magnitude greater than that of any peptide in these studies. Thus, the large quantities of Pep synthesized in pedal ganglia reflects the very high rate of transport of Pep to the periphery.

\section{Possible physiological roles for Pep}

The central and peripheral distribution of Pep suggests that it may be involved in a broad range of function. One of these may be in cardiovascular or hemodynamic control. As described above, peripheral immunoreactive varicosities were associated with vascular spaces and surrounding muscle fibers. In addition, immunoreactive networks were found on several of the cell bodies of left upper quadrant (L2-6) neurons. One function of these neurons is in the regulation of the renal pore (Koester and Koch, 1987). Similar networks were also found on neurons in the region of the abdominal ganglia in which 3 vasoconstrictor neurons have been characterized (Mayeri et al., 1974). Cardiovascular and hemodynamic control may be especially important in Aplysia since, in addition to the normal roles for the circulatory system, this system must also act as a hydrostatic skeleton for postural support and to assist in movements. We are currently investigating the physiological roles of Pep in Aplysia using the approach of identifying Pep-containing neurons and determining their functions.

\section{References}

Brown, R. O., D. Gusman, A. I. Busbaum, and E. Mayeri (1985) Identification of Aplysia neurons containing immunoreactive FMRFamide. Neuropeptides 6: 517-526.

Chiu, A. Y., and F. Strumwasser (1981) An immunohistochemical study of the neuropeptidergic bag cells of Aplysia. J. Neurosci. $1: 812-$ 826.

Cropper, E. C., P. E. Lloyd, W. Reed, R. Tenenbaum, I. Kupfermann, and K. R. Weiss (1987) Multiple neuropeptides in cholinergic motor neurons of Aplysia: Evidence for modulation intrinsic to the motor circuit. Proc. Natl. Acad. Sci. USA 84: 3486-3490.

Frazier, W. T., E. R. Kandel, I. Kupfermann, R. Waziri, and R. E. Coggeshall (1967) Morphological and functional properties of identified neurons in the abdominal ganglion of Aplysia californica. J. Neurophysiol. 30: 1288-1351.

Goldstein, R., H. B. Kistler, Jr., H. W. M. Steinbusch, and J. H. Schwartz (1984) Distribution of serotonin-like immunoreactivity in juvenile Aplysia. Neuroscience 11: 535-547.

Hening, W. A., E. T. Walters, T. J. Carew, and E. R. Kandel (1979) Motorneuronal control of locomotion in Aplysia. Brain Res. 179:231253.

Kistler, H. B. Jr., R. D. Hawkins, J. Koester, E. R. Kandel, H. W. M. Steinbusch, and J. H. Schwartz (1985) Distribution of serotoninimmunoreactive cell bodies and processes in the abdominal ganglion of mature Aplysia. J. Neurosci. 5: 72-80.

Koester, J., and U. T. Koch (1987) Neural control of the circulatory system of Aplysia. Experientia 42: 972-980.

Kreiner, T., J. B. Rothbard, G. K. Schoolnik, and R. H. Scheller (1984) Antibodies to synthetic peptides defined by cDNA cloning reveal a network of peptidergic neurons in Aplysia. J. Neurosci. 4: 2581-2589.

Landis, D. (1985) Promises and pitfalls in immunocytochemistry. Trends. Neurosci. 8: 312-317.

Lloyd, P. E. (1988) Fast axonal transport of modulatory neuropeptides from central ganglia to components of the feeding system in Aplysia. J. Neurosci. 8: 3507-3514.

Lloyd, P. E., and C. M. Connolly (1989) Sequence of pedal peptide: A novel neuropeptide from the central nervous system of Aplysia. J. Neurosci. 9: 312-317.

Lloyd, P. E., A. C. Mahon, I. Kupfermann, J. L. Cohen, R. H. Scheller, and K. R. Weiss (1985) Biochemical and immunocytological localization of molluscan small cardioactive peptides (SCPs) in the nervous system of Aplysia californica. J. Neurosci. 5: 1851-1861.

Lloyd, P. E., M. Frankfurt, P. Stevens, I. Kupfermann, and K. R. Weiss (1987) Biochemical and immunocytological localization of the neuropeptides $\mathrm{SCP}_{\mathrm{A}}, \mathrm{SCP}_{\mathrm{B}}$, and FMRFamide to neurons involved in the regulation of feeding in Aplysia. J. Neurosci. 7: 1123-1132.

Longley, R. D., and A. J. Longley (1986) Serotonin immunoreactivity of neurons in the gastropod Aplysia californica. J. Neurobiol. 17:339358 . 
Mayeri, E., J. Koester, I. Kupfermann, G. Liebeswar, and E. R. Kandel (1974) Neural control of circulation in Aplysia. I. Motoneurons. J. Neurophysiol. 37: 458-475.

Ono, I. K. (1986) Localization and identification of neurons with cholecystokinin and gastrin-like immunoreactivity in wholemounts of Aplysia ganglia. Neuroscience 18: 957-974.

Ono, J. K., and R. E. McCaman (1984) Immunocytochemical localization and direct assays of serotonin containing neurons in Aplysia. Neuroscience 11:549-560.
Schaefer, M., M. R. Piccotto, T. Kreiner, R.-R. Kaldany, R. Taussig, and R. H. Scheller (1985) Aplysia neurons express a gene encoding multiple FMRFamide neuropeptides. Cell 41: 457-467.

Schwartz, I. H. (1979) Axonal transport: Components, mechanisms, and specifity. Annu. Rev. Neurosci. 2: 467-504.

Vigna, S. R., J. L. M. Morgan, and T. M. Thomas (1984) Localization and characterization of neurons with gastrin/cholecystokinin-like immunoreactivity in the central nervous system of Aplysia californica. J. Neurosci. 5: 1370-1377. 